\title{
EFFECT OF STOCKING RATE ON PASTURE PRODUCTION UNDER IRRIGATION AND GROWTH OF YOUNG CATTLE
}

\author{
A. G. TAYLOR \\ Winchmore Irrigation Research Station, M inistry of Agriculture \\ and Fisheries, A shburton
}

Abstract

In a five-year trial, pasture and beef production of a traditional beef system using 6- to 7-month-old Angus weaner steers and a dairy beef system using 3-to 4-month-old Friesian weaner steers were compared at three stocking rates. Average production from the final four years was as follows:

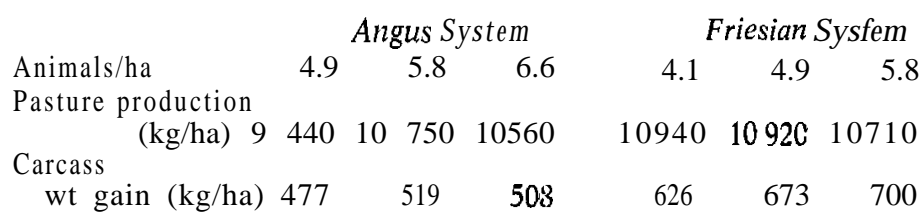

Pasture production. was significantly affected only at 4.9 animals/ ha of the Angus system. Pasture utilization percentages of over $50 \%$ produced the highest weight gain per hectare. Percentage DOM of the available pasture was affected by stocking rate and season. Higher levels were achieved by high stocking rates and during spring and early summer only.

\section{INTRODUCTION}

STOCKING RATE is one of the main factors influencing production from grazing cattle and is probably the easiest for the farmer to alter. Raising it above the level where the appetite of the animal is satisfied will result in a more efficient use of pasture but will cause a decline in intake and production of individual animals. However, production per hectare will increase until a critical level of stocking is reached where production from additional animals can no longer compensate for loss in production from the individual.

A five-year study of the effect of stocking rate on both pasture and weaner beef production was carried out at Winchmore Irrigation Research Station in mid-Canterbury on a Lismore stony silt loam. Among the objectives were: a comparison of production of 
a dairy beef system (Friesian weaners bought in November) with a traditional beef system (Angus weaners bought in April) ; establishing the relationship between stocking rate and beef production per hectare in both system's; and measuring the effect of stocking rates on pasture production. The experiment began in April 1969 and finished in March 1974.

\section{EXPERIMENTAL}

Stocking rates for each system were based on pasture production data from long-term trials on the station, and the estimated dry matter appetite of young growing cattle. High stocking rates were calculated so that animal appetite would exceed potential pasture productioa but only to the extent of ensuring full pasture utilization. The level of the low stocking rates was such that the estimated appetite would be less than pasture production, with both animal appetite snd pasture productioa being similar on the medium stocking rate.

Stocking rates were (animals wintered) :

No. of

Traditional beef system (A ngus steers) -

1. 4.9 animals/ha

2. 5.8 animals/ha

3. 6.6 animals/ha

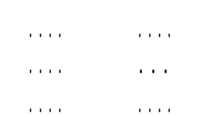

Animals

Dairy beef system (Friesian steers)
4. 4.1 animals/ha
5. 4.9 animals/ha
6. 5.8 animals/ha

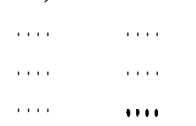
111
(1,
10
(1..'

The relative stocking rates of Friesian were set at a lower level during winter as there was an overlap of generations from late November till early March. Estimated annual total intakes were similar to those of the Angus cattle.

Each treatment, replicated twice, was grazed on a self-contained farmlet. The farmlets consisted of nine paddocks of 0.27 ha of which four we're sampled for pasture productioa. Pasture available to cattle was measured immediately before entry to each of these paddocks and pasture remaining immediately after cattle were removed. Samples were cut to ground level with a shearing machine. Pasture production and consumption were calculated from the data.

The 6- to 7-month-old Angus weaners were introduced in April each year and made a slow rotation on autumn-saved pasture 
which generally finished in early June. Two further slow rotations were made, on winter regrowth. Hay was fed only during the second and third rotations. By this method, autumn-saved pasture was grazed before deterioration from frosting took place and full use was made of winter-regrowth. Hay feeding finished in early September. The spring, and summer rotation was approximately 31 days with a 28 -day recovery period.

The 3- to 4-month-old Friesian weaners were brought in in late November and were rotated ahead of the yearlings, giving paddocks a recovery period of 21 to 25 days. During autumn, after the yearlings were slaughtered, the rotation of calves was gradually slowed down to build up a surplus of autumn-saved pasture. A mean of $37 \%$ of each farmlet on both systems was closed for hay after one rotation in spring and hay was cut in early December.

Although the systems and replicates were managed independently, the three stocking rates within each group were treated alike. They were rotated together and proportionall numbers were drafted for slaughter at the same time. Irrigation was applied equally to both systems and replicates, with a mean of 6 irrigations per year and a range of 4 to 8 . Drafting of animals for slaughter was based on feed availability and estimated pasture growth. Management decisions such as this were made on the conditions of the medium stocking rates with, if necessary, greater consideration being given to low stocking rates rather than to high. As management and method of pasture sampling were changed after the first year, data for that year have been excluded and results are means of the other four years.

\section{RESULTS AND DISCUSSION}

\section{Pasture Production, Utilization and Quality}

The pattern of production of irrigated pasture under cattle grazing and effects of stocking rates are shown in Fig. 1. As there were no significant differences in annual production, and as patterns were similar, a mean of the three rates of the Friesian system is shown. Mean annual production of the low stocking rate Angus pasture was significantly lower than the production, of all other pastures (Table 1). The differences occurred in the final two years when there was a significant decline' in production from the previous year at this stocking rate only.

Stocking rates used in this experiment were not extreme. The . low rates would be considered moderately high in a district with 


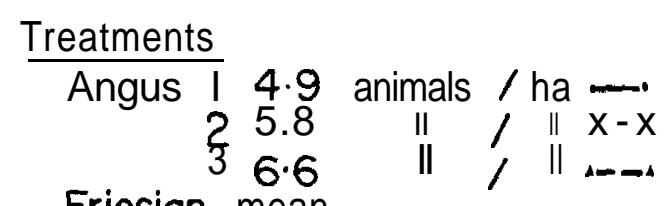

Friesian mean

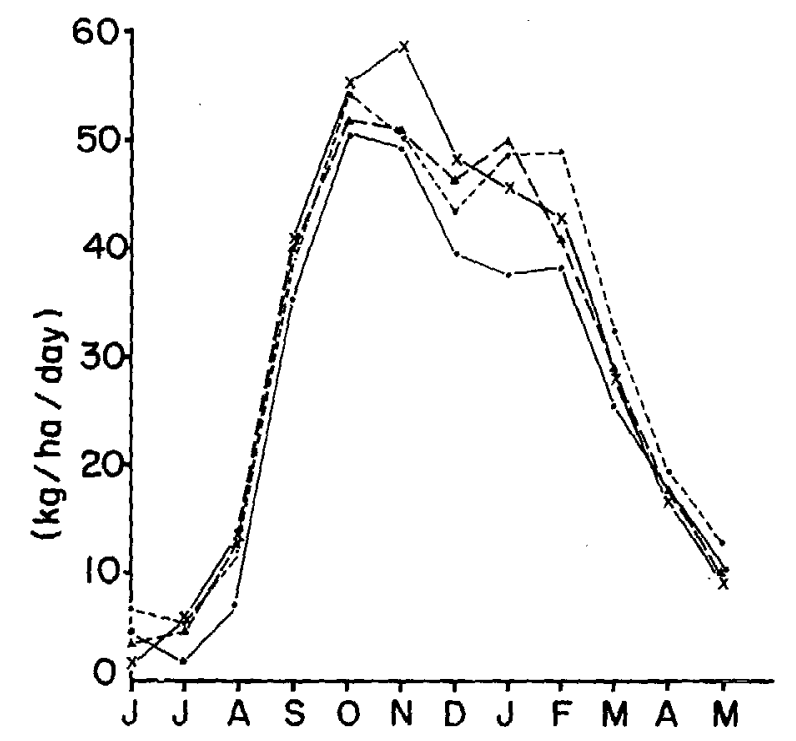

FIG. 1: Daily $D M$ production (kg/ha/day)

TABLE 1: MEAN ANNUAL PASTURE PRODUCTION

\begin{tabular}{|c|c|c|c|c|c|c|}
\hline Treatment & & & & & & $\begin{array}{l}\text { Production } \\
(\mathrm{kg} / \mathrm{ha})\end{array}$ \\
\hline $\begin{array}{l}\text { Angus: } \\
\text { Low } \ldots \\
\text { Medium } \\
\text { High }\end{array}$ & $\begin{array}{l}\cdots \\
\cdots\end{array}$ & $\begin{array}{l}\ldots . \\
\ldots . \\
\cdots\end{array}$ & $\begin{array}{l}\ldots \\
\ldots \\
\ldots\end{array}$ & $\begin{array}{l}\ldots . \\
\cdots \cdot \\
\cdots\end{array}$ & $\begin{array}{l}\ldots \\
\cdots \\
\ldots\end{array}$ & $\begin{array}{r}9530 \\
10 \quad 800 \\
10 \mathbf{5 8 0}\end{array}$ \\
\hline $\begin{array}{l}\text { Friesian: } \\
\text { L o w } \\
\text { Medium } \\
\text { High }\end{array}$ & & $\begin{array}{l}\cdots \cdot \cdot \\
\cdots \cdot \\
\cdots\end{array}$ & $\begin{array}{l}\ldots \\
\ldots . \\
\ldots .\end{array}$ & $\begin{array}{l}\ldots \\
\ldots \\
\ldots\end{array}$ & $\begin{array}{l}\ldots \\
\ldots \\
\ldots \\
\ldots\end{array}$ & $\begin{array}{ll}10 & 940 \\
10 & 920 \\
10 & 710\end{array}$ \\
\hline
\end{tabular}


very little pasture growth during winter months. The high stocking rates were set at a level estimated to be only sufficiently high

to ensure a reduction in beef production per 'hectare without necessitating the introduction of feed, in order to produce a curvilinear relationship within each system between stocking rate and beef production per (hectare. This relationship was achieved in one year in the Friesian system. Pastures at the low stocking rates were 'generally undergrazed during the seasons of pasture growth and cattle were reluctant to graze certain areas such as dung pats or close to the levees, even at times when feed availability was falling. Consequently these areas became rank and went to seed. High stocking rate paddocks were always hard grazed and herbage around and above dung pats eaten back. Few seedheads were allowed to form. Medium stocking rate pastures were intermediate and were well but not hard grazed.

Although the effect on pasture of the low stocking rates of each system appeared to be similar during most of the year, pasture production of the Friesian low stocking rate did not show a decline relative to the others. Mean daily pasture production of the Angus low stocking rate was lowest during most of the year but the main decline occurred in late summer and early autumn. A reduction in pasture production with low stocking rate or grazing pressure is not usual, as in other stocking rate trials the decline has taken place as the intensity of stocking increased. In this present trial there was no significant decline in either system with increasing stocking rate.

With the' difference in the grazing patterns between the stocking rates described above, differences in measured pasture utilizatioa would be expected. In Fig. 2, showing percentage utilization of the pastures, the year has been divided into three periods, each of which had a different aspect of management. Levels shown

TABLE 2: PERCENTAGE DEAD MATERIAL (AUTUMN-SAVED PASTURE)

\begin{tabular}{|c|c|c|c|c|c|c|c|}
\hline Treatment & & & & & & $\%$ & ad Herbage \\
\hline \multicolumn{8}{|l|}{ Angus: } \\
\hline Low & $\ldots$ & $\ldots$ & .,. & $\ldots$ & $\ldots$ & .... & 22.8 \\
\hline Medium & 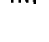 & . & (in. & $\ldots$ & al' & ... & 15.4 \\
\hline High & $\ldots$ & $\ldots$ & $\ldots$ & $\ldots 4$ & 1. & . , & 16.2 \\
\hline \multicolumn{8}{|l|}{ Friesian: } \\
\hline Low & II, & $\ldots$ & $\ldots$ & $\ldots$ & & $\ldots$ & 21.1 \\
\hline Medium & "in & & $\ldots$ & $\ldots$ & $\ldots$ & $\ldots$ & 21.0 \\
\hline High & $\ldots$ & $\ldots$ & $\ldots$ & . & $\ldots$ & $\ldots$ & 15.3 \\
\hline
\end{tabular}




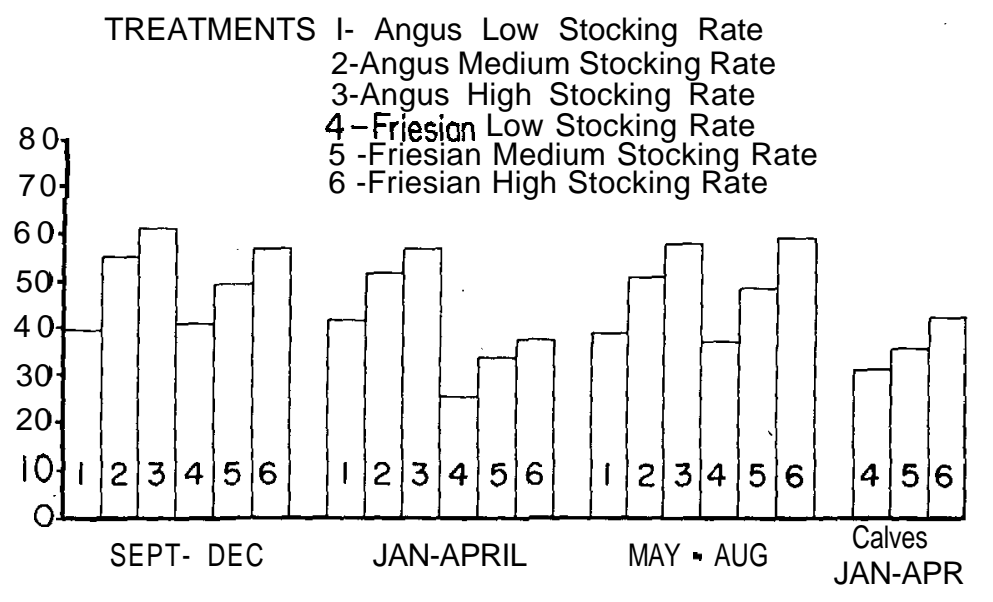

Fig. 2: Percentage pasture utilization.

are the means of single grazings as these have been shown to be the most reliable estimate of pasture utilization (Campbell, 1964) .

Pasture utilization of the Angus stocking rates remained fairly constant between seasons despite the diversity of management. Levels of the Friesians were similarly constant apart from the period January-April when grazing pressure of the yearlings was reduced by drafting. During the first half of this period, "however, when both generations were present, total pasture utilization was higher than for the equivalent Angus stacking rates. There were, nevertheless, clearly defined levels of utilization for each stocking rate and, during the first and third periods, similarity between equivalent stocking rates of the two systems.

Levels of utilization 'affected the amount of dead and decaying herbage, and quality of the feed, measured in terms of digestibility. Herbage dissection was carried out in May only of each year, and percentages of dead material are shown in Table 2 .

It is possible that earlier in the year percentages of dead herbage were higher and differences between stocking rates greater. Campbell (1964) recorded a peak of $36 \%$ dead material in February at a stocking rate of 1.33 cows/ha with an average annual percentage utilization of approximately 33\%. With the method used in this experiment, pasture production was assumed to be the difference between the samplings before grazirig and the previous samplings after grazing and that this difference included both pasture growth and decay. From the end of the spring 
flush, therefore, treatments with a high utilization may show a greater daily pasture production relative to the others with higher' amcunts of decaying matter. All treatments showed a decline in percentage of ryegrass (Lolium perenne) and an increase in cocksfoot (Dactylis glomerata), weed grasses, weeds and white clover (Trifolium repens) .

In vitro digestibility of pre-grazing cuts is presented in Fig. 3 as the monthly means of the equivalent stocking rates of both systems. Throughout the year, digestibility was generally higher on the higher stocking rates except over spring and early summer when medium and high stocking rates were similar. All treatments followed a pattern of increasing digestibility in spring, rising to a peak in October, and then falling to a low in January. The two lower treatments stayed about this level throughout autumn and winter while the high stocking rate showed a steady increase over autumn. This perhaps was a result of the lower amount of dead and decaying herbage on this treatment at this time.

\section{Mean low stocking rates \\ Mean medium stocking rates $x-x$ \\ Me a n high stocking rates}

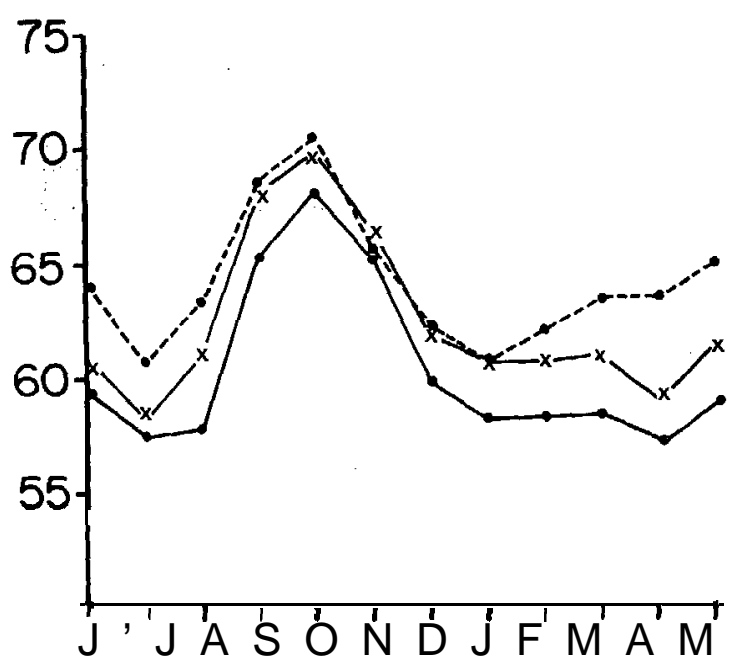

FIG. 3: Percentage digesfible organic mnfer. 


\section{Antmal Production}

Good average quality weaners of both breeds were obtained each year. The Angus average liveweight at the end of April was $209 \mathrm{~kg}$ with a range of 196 to $214 \mathrm{~kg}$. The effect of stocking rate became evident within the first month and a gradual divergence in liveweights took place from late May until the end of August (Fig. 4a). The rate of gain of the low and medium stocking rates declined, during the second, and part of the third, winter rotation. At this time cattle $\mathrm{cm}$ the high stocking rate showed a slight loss in liveweight and were slower to pick up in spring. The difference in liveweight between low and medium stocking rates occurred mainly in the winter as rate of gain of both from early spring to the end of December was similar.

In some years there was compensatory growth in the high stocking rate cattle but on the average of the four years this was very slight and lasted only until the end of October. The rate of gain then declined and the difference in liveweight between high and other stocking rates increased gradually until January. At this stocking rate and with $37 \%$ of the area closed for hay, there was insufficient feed available to realize the potential of the high stocking rate cattle for compensatory growth.

The effect of the stocking rates on the Friesian cattle became evident almost immediately. The pattern from then on was similar

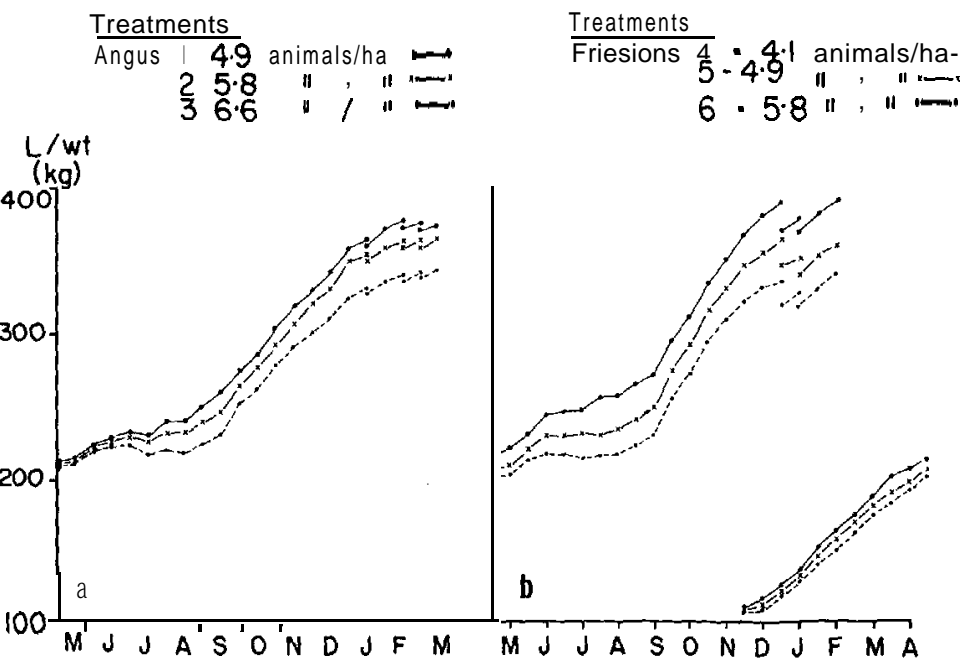

Frc. 4: Increases in liveweights $(\mathrm{kg})$ of (a) Angus and (b) Friesians. 
to that of the Angus although greater differences between the treatments in liveweight occurred by the end of December and the increase in liveweight gain was slower to begin in spring. In the Angus system, conversion ratios (Table 3) were satisfactory only in the September to December period and it was during these four months that most of the weight gain was achieved. Liveweight gains during the fallowing period, January to April, were low and the conversion ratios high. At this time the digestible organic matter percentage had dropped markedly and, although the quality of the herbage on the high stocking rates improved, the cattle had a lower plane of nutrition because the quantity of herbage was less.

TABLE 3: LIVEWEIGHT GAINS, DM INTAKES AND CONVERSION RATES (kg per day)

\begin{tabular}{|c|c|c|c|c|c|c|c|c|c|}
\hline & \multirow[b]{2}{*}{$L W G$} & \multicolumn{2}{|l|}{$L$} & \multicolumn{3}{|c|}{ Medium } & \multicolumn{3}{|c|}{ High } \\
\hline & & & $\begin{array}{l}\text { Conv. } \\
\text { Ratio }\end{array}$ & $L W G$ & Intake & $\begin{array}{l}\text { Conv. } \\
\text { Ratio }\end{array}$ & $L W G$ & Intake & $\begin{array}{l}\text { Conv. } \\
\text { Ratio }\end{array}$ \\
\hline \multicolumn{10}{|l|}{ ingus: } \\
\hline Sep.-Dec. & 0.89 & 5.75 & 6.45 & 0.90 & 5.95 & 6.62 & 0.82 & 5.14 & 6.27 \\
\hline Jan.-Apr. & 0.36 & 5.39 & 14.98 & 0.36 & 8.88 & 24.65 & 0.24 & 4.54 & 18.93 \\
\hline May-Aug. & 0.32 & 7.58 & 23.69 & 0.24 & 4.54 & 18.95 & 0.12 & 3.84 & 32.02 \\
\hline \multicolumn{10}{|l|}{ Triesian: } \\
\hline $\begin{array}{l}\text { Dec.-Feb. } \\
\text { (calves) }\end{array}$ & 0.71 & 4.36 & 6.14 & 0.67 & 4.09 & 6.11 & 0.59 & 3.45 & 5.84 \\
\hline Mar.-Apr. & 0.69 & 6.61 & 9.58 & 0.61 & 5.87 & 9.62 & 0.64 & 4.85 & 7.58 \\
\hline May-Aug. & 0.32 & 5.48 & 17.13 & 0.28 & 4.84 & 17.29 & 0.17 & 3.93 & 23.10 \\
\hline Sep.-Dec. & 1.03 & 7.15 & 6.94 & 0.99 & 7.26 & 7.33 & 0.93 & 5.59 & 96.01 \\
\hline Jan.-Feb. & 0.67 & 10.18 & 15.19 & 0.54 & 6.32 & 11.71 & 0.65 & 6.54 & 10.06 \\
\hline
\end{tabular}

TABLE 4: BEEF PRODUCTION RESULTS

\begin{tabular}{|c|c|c|c|c|c|c|}
\hline & 1 & 2 & $\underset{3}{T r e a}$ & $\begin{array}{r}\text { nent } \\
4^{*}\end{array}$ & $5^{*}$ & $6^{*}$ \\
\hline Mean hot carcass wt (kg) & 204 & 199 & 185 & 201 & 186 & 172 \\
\hline Total carcass wt/ha $(\mathrm{kg})$ & 1012 & 1147 & 1224 & 829 & 920 & 991 \\
\hline Carcass gain/animal (kg) & 97 & 90 & 77 & 152 & 136 & 122 \\
\hline Carcass gain $/ \mathrm{ha}(\mathrm{kg})$ & 477 & 519 & $50 \mathrm{~s}$ & 626 & 673 & 700 \\
\hline Conv. ratio (kg/ha $\underset{\text { carcass } \mathrm{Dt})}{\mathrm{DM} / \mathrm{kg}}$ & 19.98 & 20.80 & 20.83 & 17.48 & 16.23 & 15.30 \\
\hline
\end{tabular}

*Because of the overlap in generations of the Friesians, the carcass gains are the results of a 15-month period. 
Animal production results are summarized in Table 4. Within the Angus system, production from the medium stocking rate of 5.8 animals/ha was highest when averaged over the four years. It was $8 \%$ batter than the low stocking rate but only $2 \%$ above the high. The greatest between-year differences were 81,87 , and $98 \mathrm{~kg} / \mathrm{ha}$ for the three stocking rates, respectively.

The Friesian system was clearly more efficient in terms of carcass weight gain per hectare. It used younger and lighter animals and, as a breed, is known to have a higher growth rate. In this case the higher stocking rate showed the greatest carcass weight gain per hectate. The greatest between-year differences were 44, 70 and $23 \mathrm{~kg} / \mathrm{ha}$, respectively.

The net carcass gain, however, is not the sole criterion of beef production systems. Unlike dairying where the product remains uniform over a wide range of stocking rates, these affect the quality of the final product of beef systems, and, although treatments 3,5 and 6 were higher producing, carcasses were undesirably light.

\section{ACKN OWLEDGEMENTS}

Grateful acknowledgement is made to A. D. H. Joblin who proposed and supervised this experiment initially, to D. S. Rickard and L. J. Forsythe for in vitro analyses, and to M. Lloyd and B. M. Robinson for their assistance in the field.

\section{REFERENCE}

Campbell, A. G., 1964. Proc. N.Z. Sac. A nim. Prod., 24: 17-27. 